\title{
Development of a nozzle capillary viscometer for inline viscosity measurement of thermoplastics
}

\author{
Peter Wappler $^{1} \cdot$ Tim Horter $^{1} \cdot$ Romit Kulkarni $^{1} \cdot$ Thomas Guenther $^{1,2} \cdot$ Karl-Peter Fritz $^{1} \cdot$ André Zimmermann $^{1,2}$
}

Received: 14 June 2021 / Accepted: 16 November 2021 / Published online: 25 January 2022

(c) The Author(s) 2021

\begin{abstract}
Todays continuous improvement and advancement in the injection molding process for plastics allow for increasing reliability of the process parameter control, whereas the fluctuations of the material properties still present a great challenge. To compensate for these fluctuations, a nozzle capillary rheometer is developed with the aim to determine the viscosity inline during the injection process in series production applications. An essential part of this work is the signal processing and the definition of a suitable integration boundary to ensure a reliable signal evaluation. In addition, based on mathematical modeling and established correction factors, it is possible to determine the effective viscosity accurately without the need to replace the capillary channel according to the Bagley correction.
\end{abstract}

Keywords Thermoplastic injection molding $\cdot$ Inline rheometer $\cdot$ Viscosity $\cdot$ Nozzle capillary viscometer $\cdot$ Steady state simulation $\cdot$ Integration boundary influences

\section{Introduction}

Modern machine technology allows sufficient reproducibility of machine setting parameters, such as screw movement and pressure control. As a result, fluctuating material properties, that are difficult to control, have been identified as the main disruptive influences in the injection molding process of thermoplastic materials. The most crucial process parameter is the quality of the melt, as it has a direct effect on component quality due to flow behavior and pressure distribution within the mold.

Differences in the quality and viscosity of the melt are, among other aspects, due to the raw material used. The pellet size of the plastic granulate, the moisture content, and the proportion of reused granules influence the processing properties of the polymer. Potential damage of the material

This article is part of the Topical Collection: New Intelligent Manufacturing Technologies through the Integration of Industry 4.0 and Advanced Manufacturing.

Peter Wappler

Peter.Wappler@Hahn-Schickard.de

Hahn-Schickard, 70569 Stuttgart, Germany

2 Institute for Micro Integration (IFM), University of Stuttgart, 70569 Stuttgart, Germany due to temperature influences is another motivation for the requirement of a more detailed analysis of the melt. This occurs, for example, even during simple process interruptions such as during tool changes where the dwell time is extended. Further variations in melt quality have already been measured due to different material batches of the same material or incorrect storage conditions [1].

To improve the injection molding process, it is desirable to introduce a measurement method that is close to the process and reproducibly characterizes the viscosity of the melt during the injection process. Hopmann et al. [2] integrated pressure sensors in the hot runner to analyze the melt viscosity. Aho and Syrjälä [3] developed a slit die adjustable rheometer in a mold to determine the shear viscosity. Generally, nozzle viscometers are tool-independent and offer the possibility of inline viscosity measurements with little conversion effort. Previous implementations of nozzle viscometer concepts mainly employed a slit die geometry, due to the simple integration of the sensors directly on the melt surface.

Following some solutions with different objectives of investigation are presented.

Cavic investigates the suitability of a viscosity index as a key performance indicator for process monitoring [4], p. 28. Gornik used a slit die nozzle rheometer for powder injection molding. He investigated three methods for checking stainless steel powder feedstock quality in 
powder injection molding and used a MFQ (monitoring of feedstock quality) method by analyzing the plasticizing torque, the bypass nozzle as an online measurement and a slit die nozzle rheometer [5]. Fernandez uses a slit die nozzle rheometer for material characterization of PP (polypropylene) and recycled PP. He determines the model coefficients for calculating the shear- and temperaturedependent viscosity based on the Carreau WLF model. The corrected material parameters result in a better agreement between simulation and experiment [6]. Eben determines the apparent viscosity of PP. Proves that the viscosity determination with a slit die nozzle rheometer is more accurate than by plastification torque, the integral of the cavity pressure over time or the integral of the screw force over the stroke [7], p. 45. Kruppa used a slit die nozzle rheometer with an interchangeable flow channel. In addition, he describes in his paper how he defines the integration limits of the pressure signals in order to calculate a viscosity index [8], p. 33. Geyer investigates the influence of additives on viscosity. He characterizes the zero viscosity and shear thinning behavior based on Carreau's law [9]. The effect of pressure on viscosity analyzed Volpe by a nozzle rheometer with different slit die geometries. Based on the Cross Vogel Model, he characterized the pressure coefficient to a more precise determination of the viscosity [10].

The slit die geometry offers the advantage of better accessibility of the pressure sensors to the melt surface and makes a Bagley correction [11] unnecessary, as may be otherwise required for circular capillary cross-sections due to the inlet pressure drop. However, higher melt loads apply compared to the capillary cross-sections. This is based on the fact that on the one hand, the cross-section in a slit die is larger, which results in a higher residence time, and on the other hand, higher shear rates due to the flat gap. None of the mentioned publications elaborates on the details of data processing, which is of importance to determine pressure differences.

An implementation with pressure sensors positioned before and after a circular capillary cross-section, similar to a laboratory capillary rheometer, requires consideration of the inlet and outlet pressure drop. In previous nozzle capillary viscometers, the capillary channel was designed to be interchangeable in order to generate different capillary dimensions with the same L/D (length to diameter) ratio and, thus, to determine the inlet pressure drop accordingly. However, these designs are bulky and usually not intended for mass production.

This paper deals with the development of a nozzle capillary viscometer (NCV) for use in series production with the aim to determine the viscosity inline during the injection process. An essential part is the signal processing and the definition of a suitable integration boundary to calculate an average pressure value of high dynamic sensor signals. This ensures a reliable signal evaluation and better signal-to-noise-ratio. In addition, based on mathematical modeling and established correction factors, it should be possible to determine the effective viscosity accurately without the need to replace the capillary channel.

The NCV provides important process information for the subsequent use of AI (artificial intelligence) methods for process optimization. A good summary of current developments in this research area is given by Weichert et al. [12], Fernandes et al. [13], and Kashyap and Datta [14]. For these methods, a relative and not necessarily an absolute statement about a viscosity variation is of particular importance.

\section{Conception}

The measuring principle of the NCV is based on a capillary rheometer. For this purpose, the plastic melt is pressed with a defined volume flow rate through a channel with a circular cross-section (capillary). The pressure loss in the capillary is measured in order to be able to calculate the melt viscosity with this information [15]. In a simplified case, the viscosity $\eta$ of a Newtonian fluid in the channel can be described with formula (1):

$\eta=\frac{\Delta p \cdot \pi \cdot r^{4}}{L \cdot 8 \cdot Q}$

with: $\Delta p=$ pressure drop along the capillary.

$r=$ radius of the capillary.

$L=$ length of the capillary.

$Q=$ volume flow.

For the conception of the NCV, it is important to consider the viscoelastic flow behavior of the polymer melt. A compression of the polymer molecule chains in the capillary results in an inlet pressure drop depending on the volume flow. In Fig. 1, this effect is illustrated by the pressure distribution along the channel. The Correction factor $e_{R}$ represents the additional channel length to a corresponding channel without inlet pressure drop. The influence of this effect is significant over the entrance length until the flow is fully developed.

The one-dimensional basic equations of the streamline theory for incompressible flows describe the momentum equation of an equilibrium of forces between pressure and velocity for each infinitesimally small volume [17]. According to this flow theory, an additional pressure drop in the capillary is to be expected. This flow phenomenon is also known as Venturi effect, which describes an additional pressure drop depending on the flow velocity.

A design for the NCV is shown in Fig. 2. If the flow cross-section in the channel constriction decreases, the plastic melt is accelerated to a higher flow velocity. 


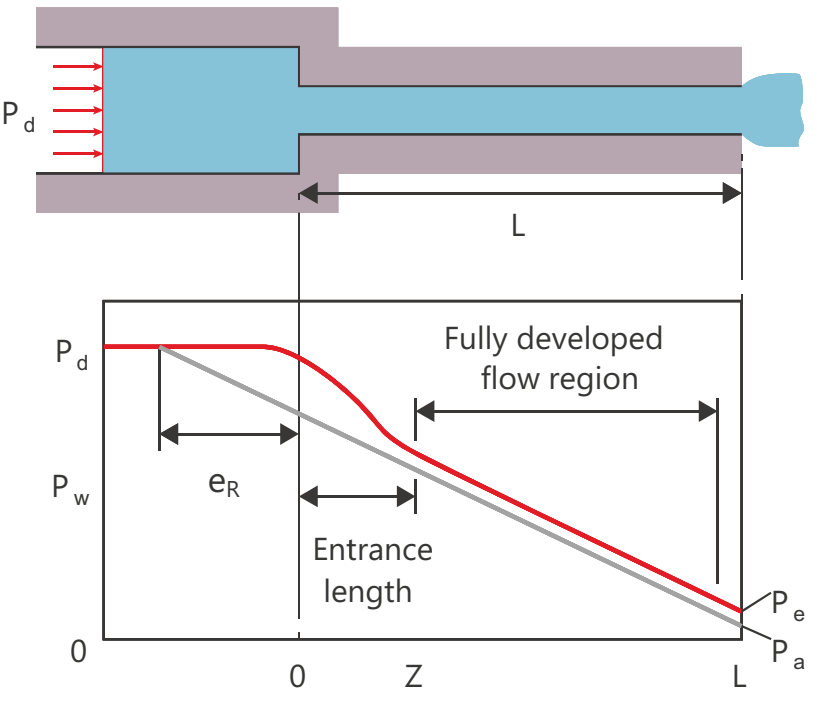

Fig. 1 Inlet pressure drop based on viscoelastic flow properties [16], p. 199

The viscoelastic phenomena lead to a higher pressure difference between the capillary inlet (Fig. 2, position 1) and the capillary (Fig. 2, position 2).

Formula (2) describes $\Delta p_{v}$ the viscoelastic pressure drop and (3) describes $\Delta p_{13}$, the total pressure loss between sensor 1 and 3 .

$\Delta p_{v}=p_{1}-2 \cdot p_{2}+p_{3}$

$\Delta p_{13}=p_{1}-p_{3}$

The nozzle channel constriction, which is to act as a capillary, is located in the center of the nozzle. Suitable sensors of type 4021 B20 HAP1 from Kistler for melt pressure and melt temperature measurement are integrated at the positions 1 to 3 as marked in Fig. 2. The measuring device is installed between the plasticizing unit at position 4 and the nozzle tip at position 5. During the injection process, the melt continues to flow through the NCV into the cavity of the mold.

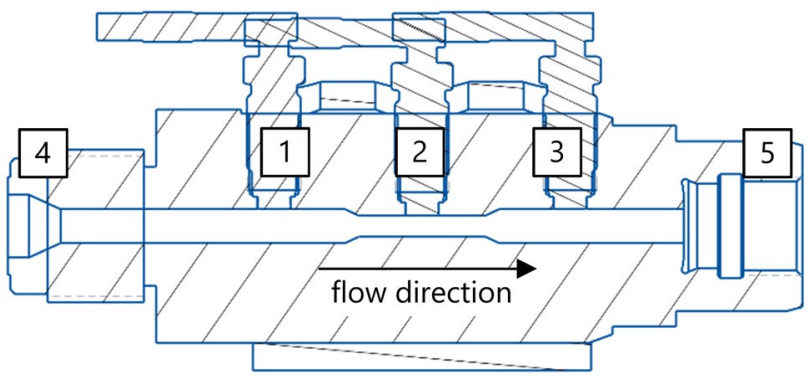

Fig. 2 Measuring concept of nozzle capillary viscometer with (1-3) integrated p-T-sensors, (4) plasticizing unit thread and (5) nozzle tip thread

\section{Simulation}

The focus of the simulation is on the design of the channel geometry so that the melt load does not exceed a defined maximum according to the predefined boundary conditions.

The boundary conditions defined for the application are:

- The capillary cross-section should be adequately sized so that the shear and temperature stress on the melt and the resulting pressure drop do not exceed a critical value and thus restrict the process window too much for operation in industrial production environments.

- Based on the first definition, the pressure drop over the entire nozzle length should not exceed a maximum of $10 \%$ of the injection pressure $(<200$ bar $)$.

- The process window for the volume flow is defined from 10 to $25 \mathrm{~cm}^{3} / \mathrm{s}$.

- Polyamide 6 designation "Durethan BKV30 H2.0" (30\% glass fiber content) from the manufacturer Lanxess.

The following boundary conditions are defined for the fluid mechanical design of the NCV:

- The flow condition is stationary.

- The plastic melt is incompressible.

- The fluid flow is considered to be laminar.

- Inertial and gravitational forces are negligible compared to frictional and compressive forces.

- The adhesion condition for the plastic melt to the channel wall applies.

- The homogeneous pressure distribution is transverse to the flow direction.

- The calculation is carried out with constant thermodynamic parameters (density, heat capacity and thermal diffusivity) of the melt.

- Adiabatic mold walls are assumed.

- Uniform melt temperature in the inlet cross section.

For the design of the nozzle channel, different geometric variations are investigated in regard to the defined boundary conditions. For this purpose, both the phase angle of the pipe transition and the channel ratio length to diameter (L/D) are varied. After determining a suitable meshing, the flow properties in the NCV during the injection process are simulated based on material data of PA6 from Ansys and Moldflow databases, listed in Table 1.

For the evaluation of the simulation, the focus is directed toward the following criteria:

- Pressure drop along the entire length of the channel 
Table 1 Viscosity parameters of PA6 BKV30 H2.0 Lanxess based on Cross-WLF (Williams-Landel-Ferry) model

\begin{tabular}{lll}
\hline Cross-WLF-coefficients: & Value & Unit \\
\hline n: power law index & 0.3841 & - \\
$\tau$ : shear stress at transition & 109,608 & $\mathrm{~Pa}$ \\
D1: Viscosity at reference temperature & $5.7347 \mathrm{e}+18$ & $\mathrm{~Pa} \cdot \mathrm{s}$ \\
D2: Reference temperature & 323.15 & $\mathrm{~K}$ \\
D3: Factor describing the pressure dependency & 0 & $\mathrm{~K} / \mathrm{Pa}$ \\
A1: Factor describing the temperature depend- & 44.663 & - \\
ency & 51.6 & $\mathrm{~K}$ \\
A2: Factor describing the temperature depend- & 553.15 & $\mathrm{~K}$ \\
ency & & \\
T: Melt temperature & & \\
\hline
\end{tabular}

- Temperature increase of the fluid

- Maximum shear rate

- Formation of backflow or dead water areas

The critical area in the capillary inlet is the transition angle shown between the constriction and the outlet. Fig. 3 shows that the shear rate is also highest in this section of the capillary channel. The material manufacturer specifies the maximum permissible shear stress of $60,000 \mathrm{~s}^{-1}$. The calculated maximum shear rate in the $\mathrm{NCV}$ is $5160 \mathrm{~s}^{-1}$ and thus below the limit. The temperature rise in the melt and the maximum shear rate occurring in the nozzle channel can be lowered toward the defined value range by reducing the opening angle from 118 (Fig. 3 right) to $70^{\circ}$ (Fig. 3 left).

Simulations of different L/D capillary ratios and opening angles at the diameter transitions result in a suitable capillary channel with a diameter of $5 \mathrm{~mm}$, a capillary length of $30 \mathrm{~mm}$, and an opening angle of $50^{\circ}$.

The pressure distribution over the entire channel length shown in Fig. 4 illustrates the different pressure gradients as a function of the volume flow. It is observable which pressure drop is expected and how the pressure gradient increases in the smaller channel cross-section.
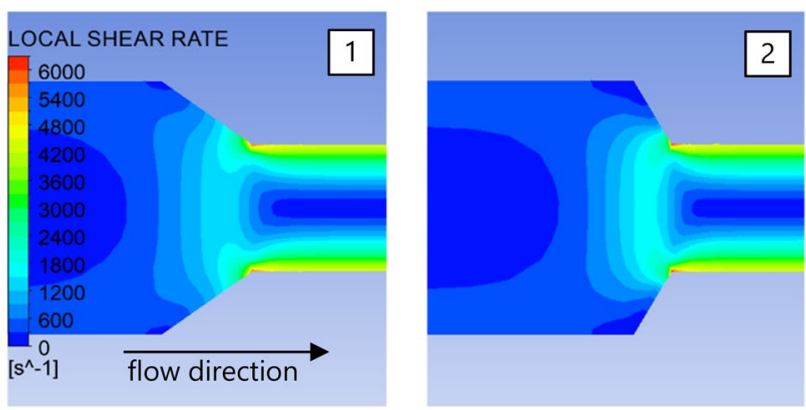

Fig. 3 Calculated shear rate at opening angles of $70^{\circ}(1)$ and $118^{\circ}(2)$

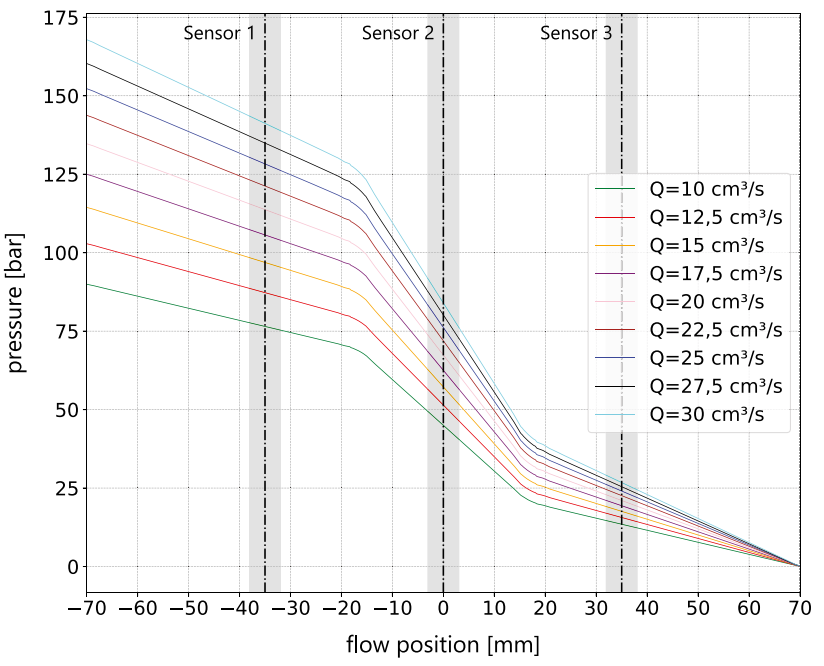

Fig. 4 Simulation result of the pressure distribution over the capillary channel length at different volume flows

For the measurement of pressure and temperature in the cross-sectional constriction of the flow channel, a sensor with a measuring membrane diameter of $8 \mathrm{~mm}$ needs to be inserted into a smaller channel diameter of $5 \mathrm{~mm}$. High shear stresses and backflow areas due to high velocity changes caused by the cross-section widening is likely. In a separate simulation, the extent to which these flow characteristics occur with the selected geometry is validated.

The channel geometry specified in the design is used as the geometry. Figure 5 shows the FEM meshing of the 3D model with a partial section along the capillary channel. For a better underflow of the sensor surface, it is connected to the channel by means of an opening funnel.

The temperature distribution along the measuring channel shown in Fig. 6 is not significantly changing by the insertion of the sensor. According to the simulation

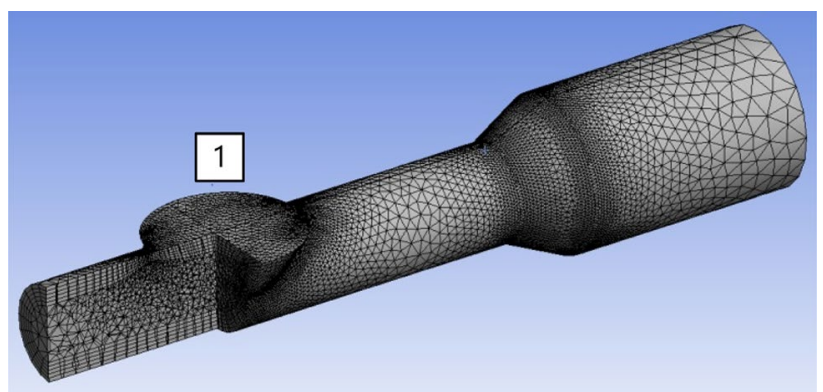

Fig. 5 FEM-Meshing of the channel cutout with opening funnel to the sensor surface at Position 1 


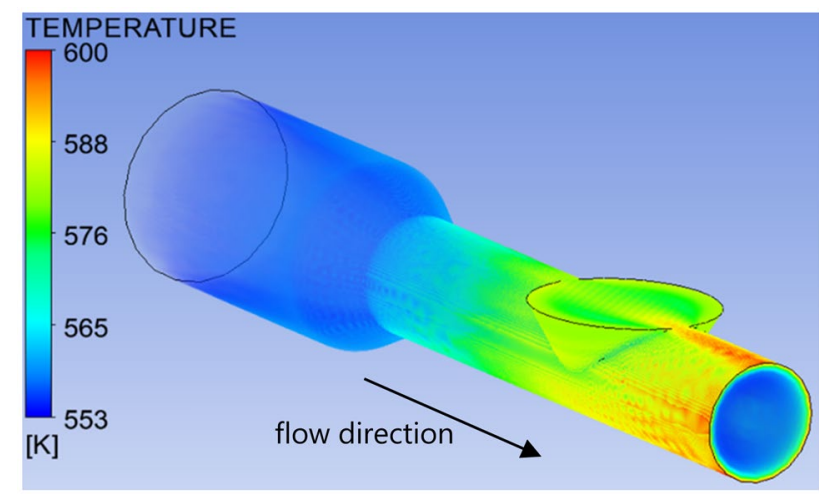

Fig. 6 Temperature evaluation Channel section

result, no excessive increase or measurement jumps in temperature are to be expected.

Further analysis of the simulation results did not reveal any other undesirable or unexpected phenomena. With regard to pressure distribution, temperature and shear stress or possible backflow effects in the orifice funnel, the calculated results are uncritical and will not be listed further here.

\section{Implementation and tests}

All machines and measuring devices used in the experimental investigations are listed below.

- Injection molding machine: Arburg - ALLROUNDER A270

- Inline melt sensors: Kistler - Type 4021B

- data acquisition system: IMC - CRONOSflex

- Software Tools for data processing: IMC - Studio 5.2 R9, Python V3.6

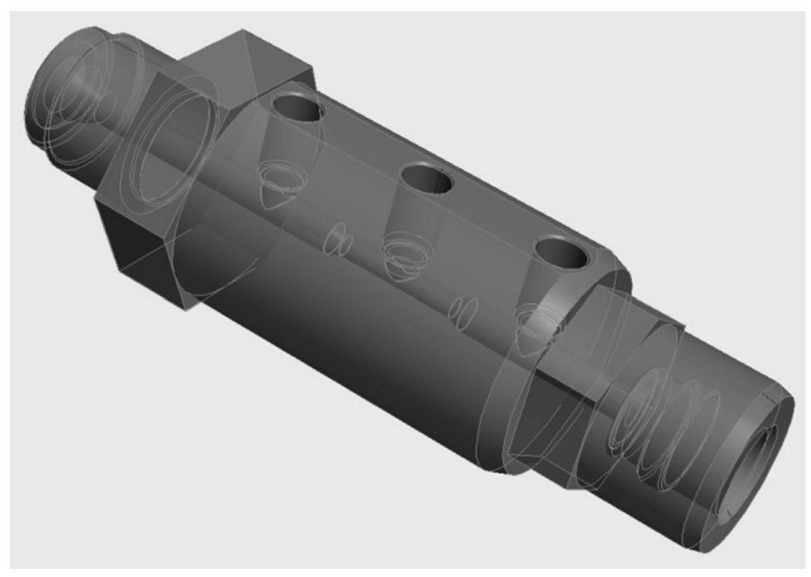

Fig. 7 CAD model of the nozzle capillary viscometer

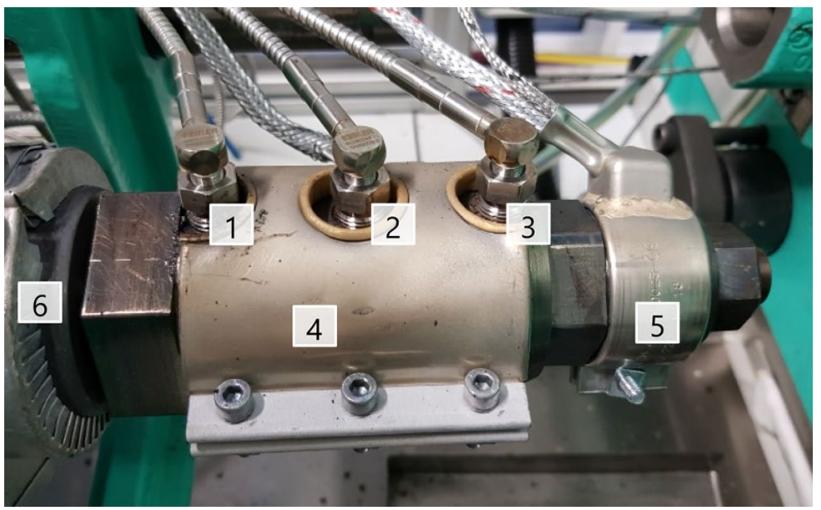

Fig. 8 Nozzle capillary viscometer equipped with three sensors (1 to 3 ) and two heating clamps (4 and 5) mounted on the plasticizing unit (6)

Figure 7 shows the generated 3D model of the finished construction.

The NCV has an overall length of $188 \mathrm{~mm}$. The crucial criterion for defining the overall length is the sensible positioning of the sensors, whereby assembly and metrological aspects are included in the determination.

Subsequent to mechanical production of the NCV, all tests are carried out on an Arburg type A270 injection molding machine. The setup of the measuring device can be seen in Fig. 8. The raw material PA6 is available in granular form and processed in accordance with the manufacturer's specifications on the degree of dryness and other processing parameters.

In addition to the sensor data, the recorder interface of the injection molding system is read out. The recorder interface supplies data on the screw position and the screw pressure as an analog voltage signal during the injection molding process.

A hardware and software readout modules are designed to process and store the signals. Using the programming language Python, these data is analyzed and visualized offline.

Figure 9 provides an overview of the evaluation process.

The following parameters are varied during the tests to determine their influence on the measurements:

- Volume flow

- Process temperature

- Moisture content of the pellets

- Dosing volume

- Switching volume

In the further sections, only the influence of the volume flow on the flow property is considered.

The injection phase can either be controlled by pressure or volume flow. Since no cavity is filled during the tests, the injection phase is controlled by volume flow in all tests. 

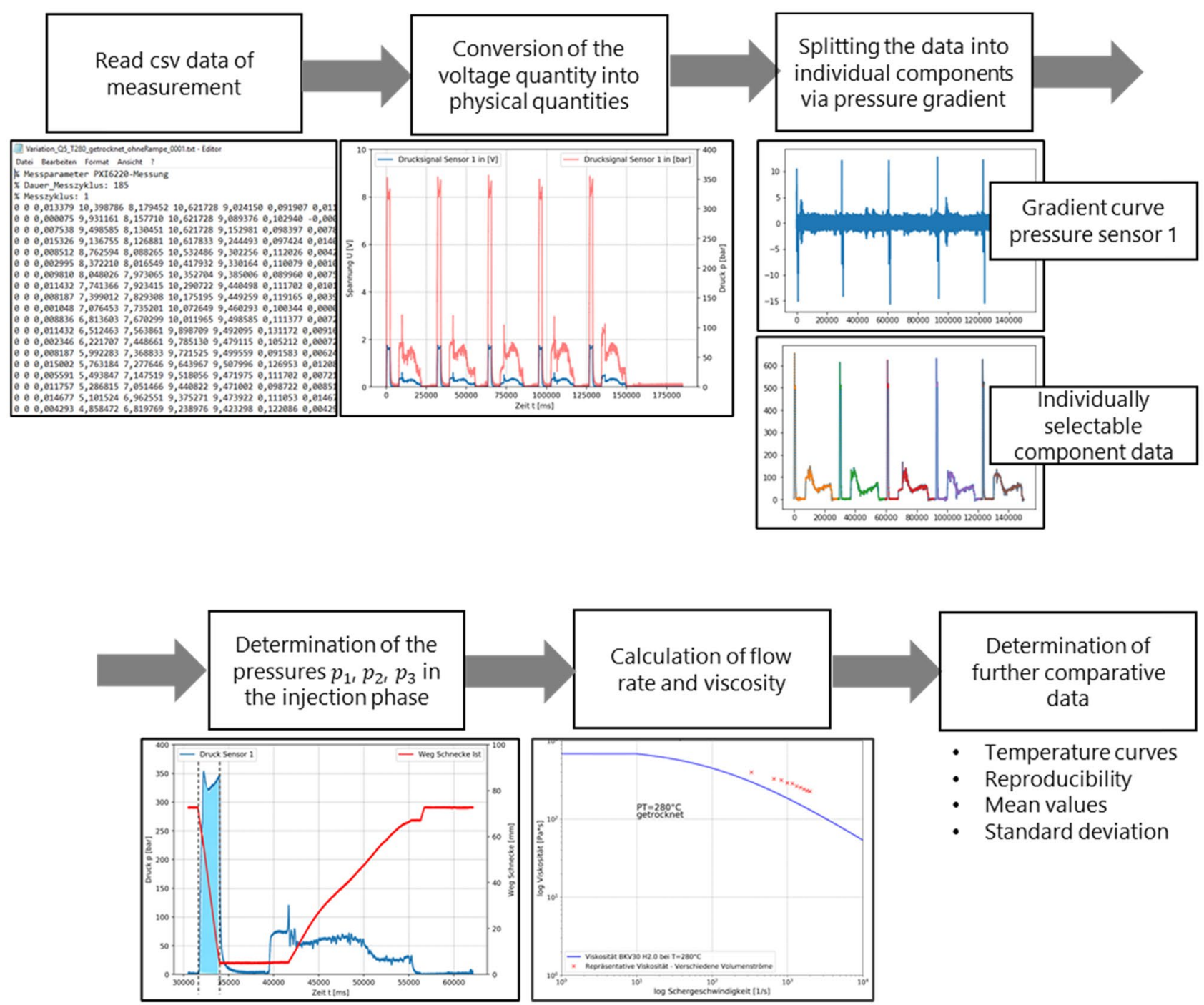

Fig. 9 Procedure for the evaluation in Python

\section{Results and discussion}

From the evaluation of the temperature signals in Fig. 10, it can be seen that the average melt temperature at nozzle sensors 1 and 3 is about $27^{\circ} \mathrm{C}$ and sensor 2 even $38{ }^{\circ} \mathrm{C}$ above the set processing temperature of $280{ }^{\circ} \mathrm{C}$.

Possible causes for this discrepancy could be attributed to the following arguments:

- The metering work of the screw induces a significantly higher heat input into the melt cushion than expected.

- An unknown disturbance variable in the control system influences the temperature control variable - e.g. temperature sensor position is unsuitable.
- A calibration offset of the sensor measuring unit.

A $10{ }^{\circ} \mathrm{C}$ higher temperature was observed at sensor 2 than at sensors 1 and 3 .

A thermal-stationary simulation resulted in a temperature difference, due to convection and heat dissipation at the rear and front of the nozzle, with less than $0.2^{\circ} \mathrm{C}$ between sensor 1 and sensor 2 . An inhomogeneous tempering of the nozzle by heating clamps cannot explain the difference in temperature.

One possible reason for the $10{ }^{\circ} \mathrm{C}$ higher temperature measurement of sensor 2 may be the dissipative shear heating during the injection phase. It seems plausible that the capillary section has a higher temperature, due systematic heating by cycle to cycle. 


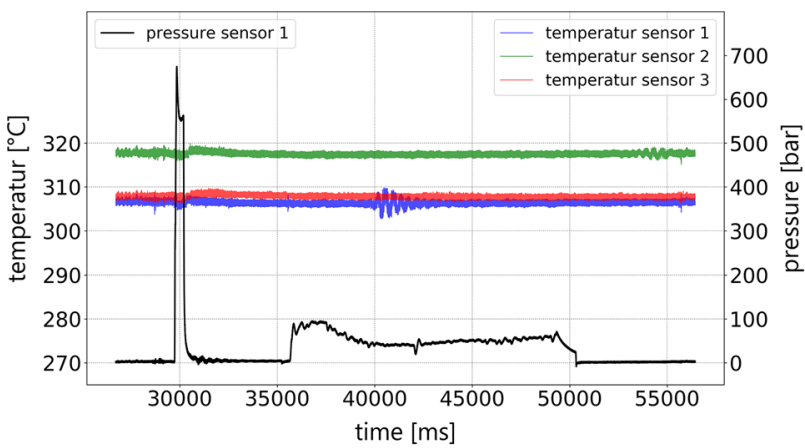

Fig. 10 Temperature signals of sensors 1,2 and 3 at volume flow of $25 \mathrm{~cm}^{3}$ /

Future tests will investigate the temperature deviation depending on screw rotation speed during dosing phase and total cycle time.

Figure 11 shows an example of the pressure sensor 1 in the NCV and screw position.

The forward movement of the screw position (red) results in a pressure increase in the NCV (blue). The dynamic overshot of the pressure signal at the beginning of the injection phase is noticeable. The unsteady flow behavior can probably be attributed to inertial forces of the moving masses and to the viscoelastic flow behavior.

For the quantification of the pressure differences in the $\mathrm{NCV}$, an average pressure value of the respective sensor signal is to be determined. Since the pressure curve exhibits unsteady flow behavior at the beginning of the injection phase, investigations are required if the measured signal is suitable to calculate the mean value and, consequently, to determine further processing parameters such as injection work.

Accordingly, the investigation of the data evaluation focuses on the definition of the left integration boundary and how it influences the mean value calculation. Furthermore, it is evaluated to which extent shifting of the left integration boundary is suitable for the further process parameter analysis.

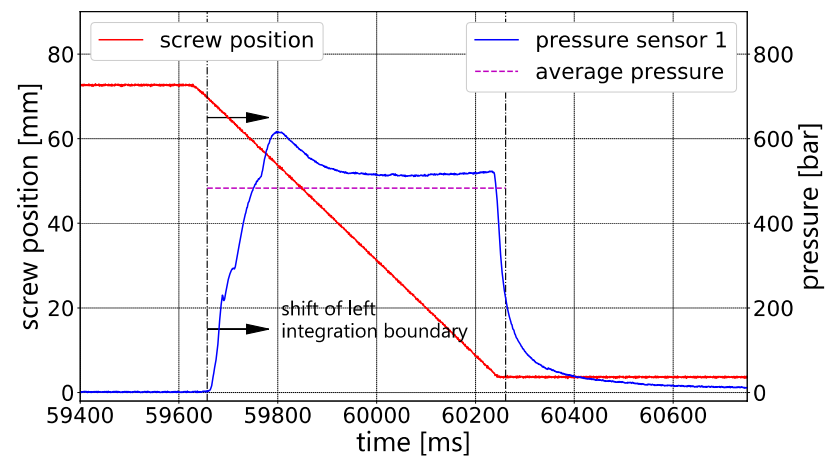

Fig. 11 Sensor pressure injection phase

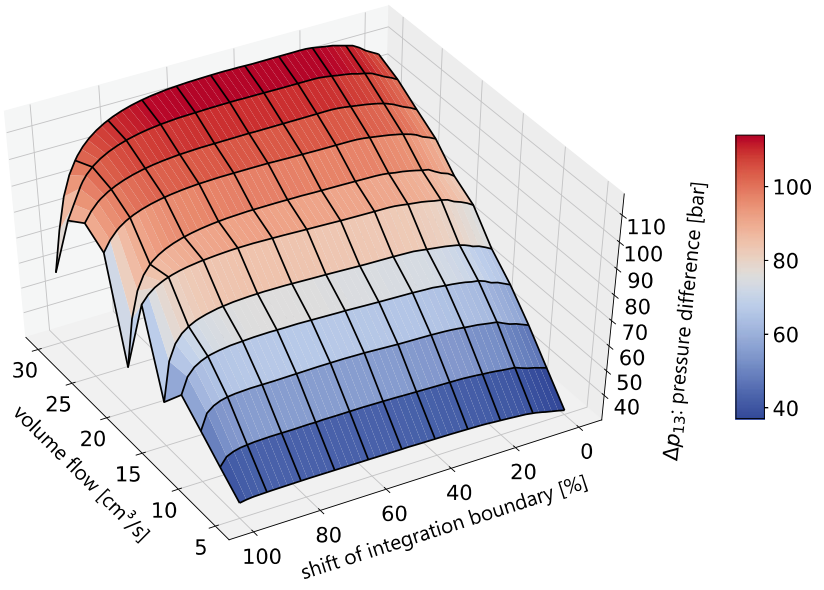

Fig. 12 Averaged injection pressure difference $\Delta p_{13}$ over volume flow and the shift of the left integration boundary

Figure 12 describes the averaged injection pressure difference between nozzle pressure sensor 1 and 3 over the volume flow and the shift of the left integration boundary. As can be seen from the diagram, the shift of the left integration boundary significantly influences the injection pressure difference for the first $20 \%$, whereas the pressure difference starts to decrease at a further shift above $70 \%$. Subsequently, the standard deviation of the individual measurement tests at the respective measuring point is used to provide a statement for the reproducibility of these measured values.

As Fig. 13 shows, the standard deviation of the injection pressure difference $\Delta p_{13, S t d}$ is insignificantly influenced by the shift of the left integration boundary, except for the shift range greater than $70 \%$.

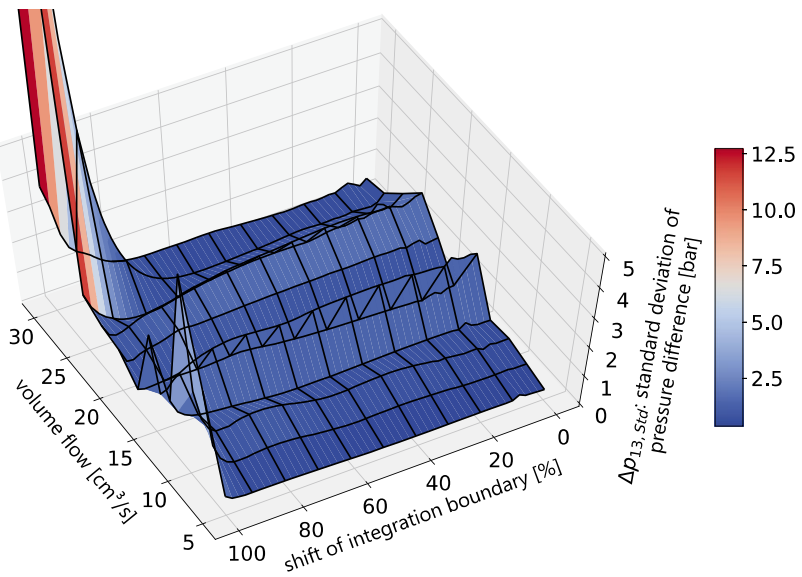

Fig. 13 Standard deviation of the injection pressure difference $\Delta p_{13, S t d}$ over volume flow and the shift of the left integration boundary 


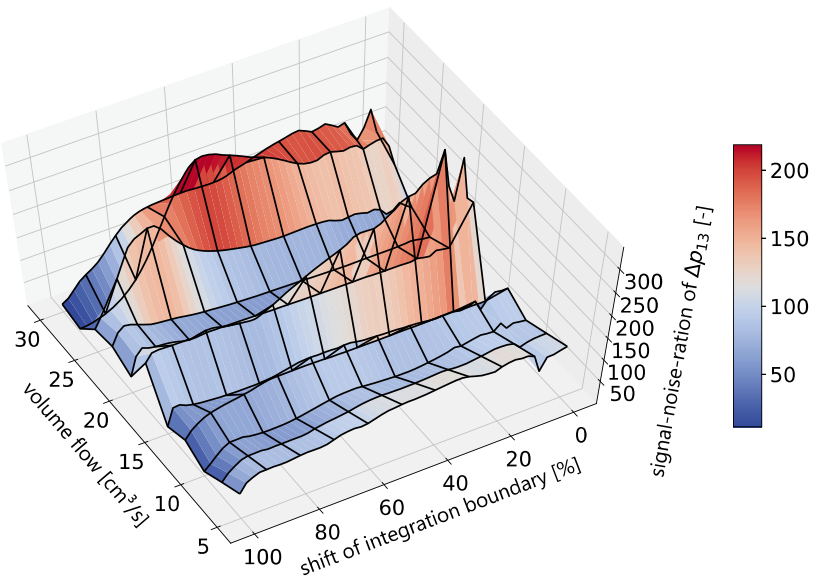

Fig. 14 Signal-to-noise-ratio of $\Delta p_{13}$ versus volume flow and shift of the left integration boundary

In order to be able to evaluate the signal quality, the signal-to-noise-ratio of the pressure difference $\Delta p_{13}$ and $\Delta p_{v}$ is calculated and plotted in Fig. 14 and Fig. 15. Moving the integration boundary above $60 \%$ results in a lower signal-to-noise-ratio.

For better evaluation, Fig. 16 visualizes the averaged signal-to-noise-ratios over the volume flows. According to the result, the signal quality of $\Delta p_{13}$ can be optimized by about $20 \%$ by an integration boundary shift of 15 to $60 \%$. Based on this result, an integration boundary shift of $20 \%$ appears most suitable for the further signal processing.

The same evaluation was carried out for the right integration boundary shift. However, no significant improvement of the signal-to-noise-ratio was achieved; hence, the right integration limit was not shifted.

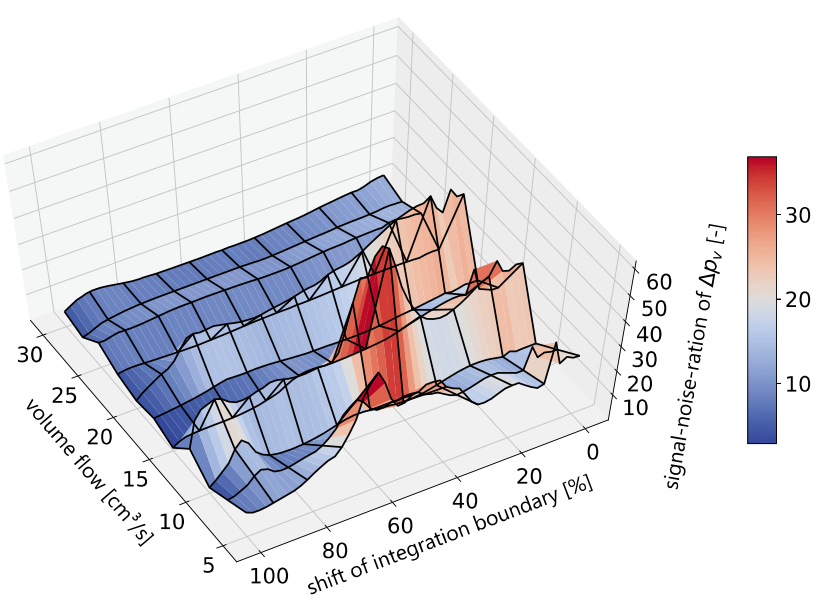

Fig. 15 Signal-to-noise-ratio of $\Delta p_{v}$ versus volume flow and shift of the left integration boundary

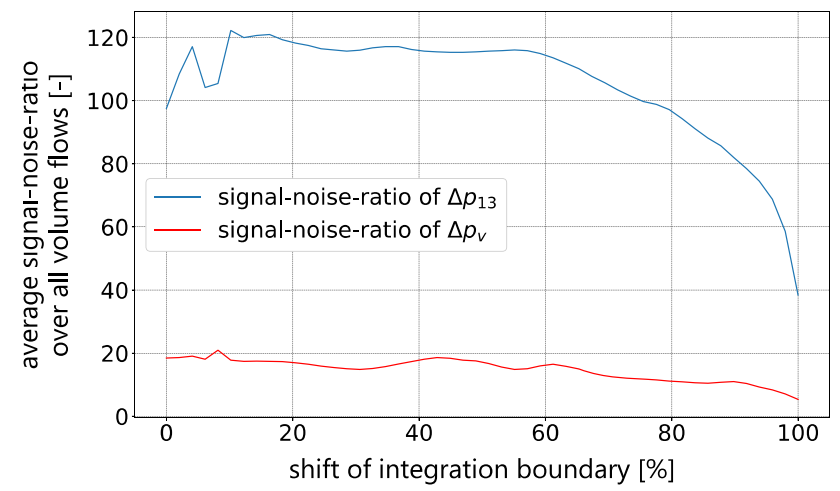

Fig. 16 Averaged signal-to-noise-ratio of $\Delta p_{13}$ and $\Delta p_{v}$ over volume flow and the shift of the left integration boundary

Figure 17 illustrates the corresponding averaged signals of the pressure differences $\Delta p_{13}$ and $\Delta p_{v}$ over different volume flows $Q$. The pressure differences $\Delta p_{13}$ and $\Delta p_{v}$ have a reproducible characteristic curve over the volume flow.

The calculated curve of the FEM simulation is in accordance with the experimental measurements in Fig. 17. Slight deviation occurs at lower volume flows. The measured pressure difference $\Delta p_{13, E x p}$. at $5 \mathrm{~cm}^{3} / \mathrm{s}$ is about 8 bar below the calculated pressure difference $\Delta p_{\text {Sim }}$ A possible reason for the qualitative deviation could be a decreasing residual moisture content in the plastic granules, since the granules remained in the drying unit throughout the test series.

Based on these results, the pressure difference can be determined precisely, the next step is to create a mathematical model to determine the viscosity.

As can be seen in Fig. 2, pressure sensors 1 and 3 are not located immediately upstream and downstream of the capillary channel. Therefore, the pressure difference $\Delta p_{13}$ includes not only the pressure loss in the 5-mm capillary channel but also in the $8 \mathrm{~mm}$ section before and after it. For the mathematical modeling, it was therefore assumed that the pressure loss consists of 3 channel sections. As a simplification, the channel is divided into the following two sections $\mathrm{a}$ and $\mathrm{b}$, section a for the $5 \mathrm{~mm}$ and section $\mathrm{b}$ for the both $8 \mathrm{~mm}$ diameter Channels.

\begin{tabular}{lll}
\hline Section & a & b \\
\hline Channel diameter & $5 \mathrm{~mm}$ & $8 \mathrm{~mm}$ \\
Channel length & $32 \mathrm{~mm}$ & $42 \mathrm{~mm}$ \\
\hline
\end{tabular}

With regard to the flow properties, the following assumptions are made: The density change is assumed to be zero, i.e. $\Delta \rho=0$. Consequently, the volume flow $Q$ is equal in both sections, described in formula (4) [18], p. 238. 


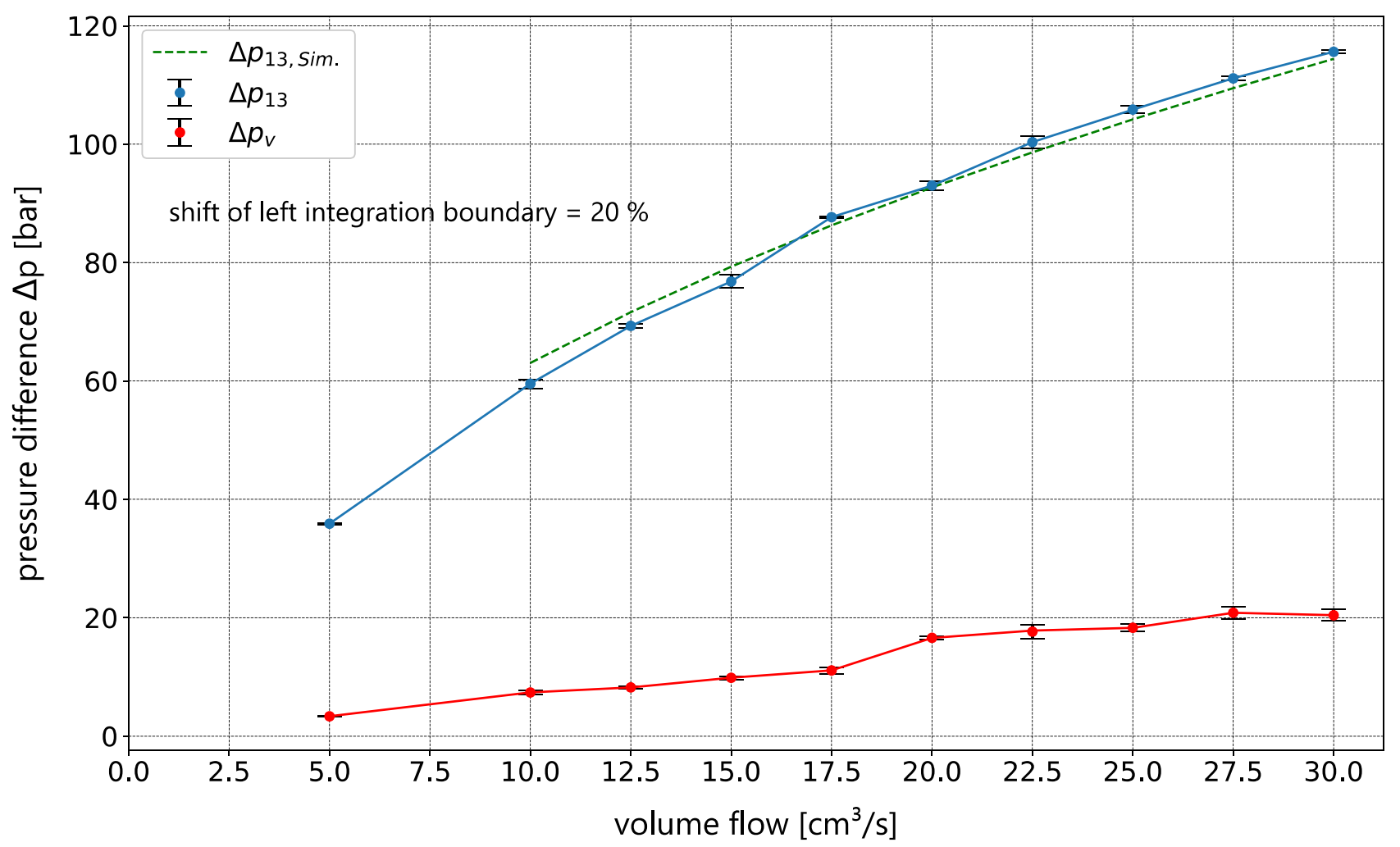

Fig. 17 Pressure differences $\Delta p_{13}$ and $\Delta p_{v}$ at different volume flows (left integration boundary shift 20\%)

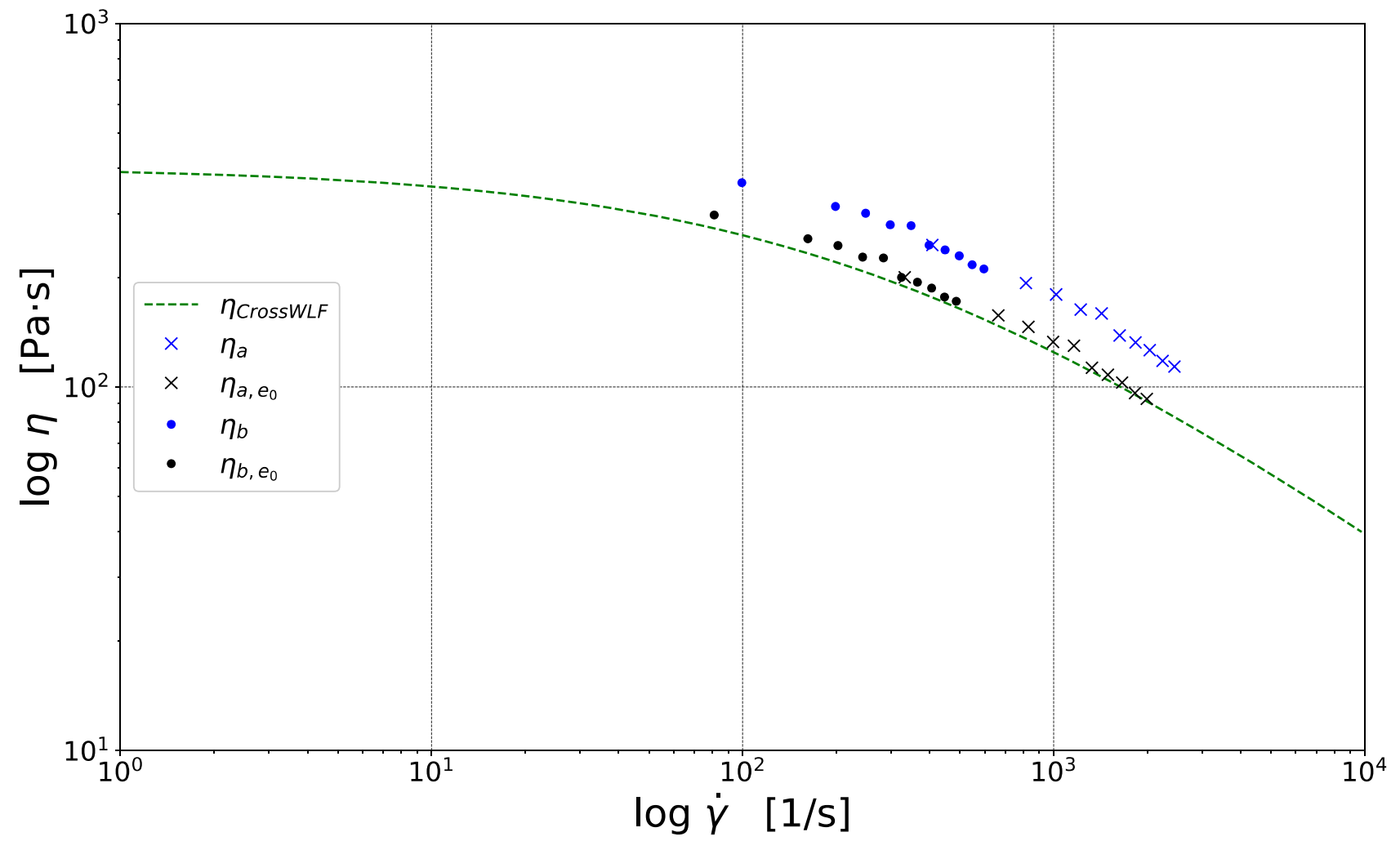

Fig. 18 Comparison of the measured representative viscosity to the Cross-WLF model based on the material data 
$Q_{a}=Q_{b}=Q=\frac{\dot{\gamma} \cdot \pi \cdot r^{3}}{4 \cdot e_{0}}$

With $Q$ :volume flow.

$\dot{\gamma}$ :shear rate.

$r$ : channel radius.

$e_{0}:$ Schümmer correction parameter to determine the representative viscosity.

The introduction of the concept of representative viscosity allows for a correction of the shear rate curve by introducing an empirically determined correction factor $e_{0}(0.815$ for thermoplastics) and, therefore, represents a simplified form of calculation [19].

Furthermore, the pressure difference $\Delta p_{13}$ is the sum of all pressure losses over the channel including the Inlet pressure drop $\Delta p_{v}$ due to the viscoelastic portion, described in formula (5).

$\Delta p_{13}=\Delta p_{a}+\Delta p_{b}+\Delta p_{v}$

With assumption (5) the corrected pressure drop $\Delta p^{*}$ can be calculated without the viscoelastic component

$\Delta p_{13}-\Delta p_{v}=\Delta p_{a}+\Delta p_{b}=\Delta p^{*}$

The average signal-to-noise-ratio of $\Delta p^{*}$ with a left integration boundary shift of $20 \%$ is 58.38 . This corresponds to a measuring inaccuracy of $1.71 \%$. In previous investigations, a pressure drop of $5 \%$ could be determined due to residual moisture fluctuation in the plastic granulates and a pressure drop of $7.5 \%$ due to melt temperature rise of $5 \mathrm{~K}$. The calculated measuring inaccuracy of $1.71 \%$ of the NCV appears to be sufficient to detect significant residual moisture and melt temperature fluctuation.

The viscosity function based on Cross-WLF-Model [16], p. 74 is transformed in a Carreau notation in formula (7). Based on the results in Fig. 10, an actual melt temperature of $307{ }^{\circ} \mathrm{C}$ is assumed for the determination of the model parameters $A, B$ and $C$.

$\eta=\frac{\tau}{\dot{\gamma}}=\frac{A}{1+(B \cdot \dot{\gamma})^{C}}$

With $\eta$ :viscosity.

$\tau$ :shear stress.

$\dot{\gamma}$ :shear rate.

$A$ : zero-viscosity.

$B$ : relation of zero-viscosity to critical shearstress at the transition zone.

$C$ : dimensionless flow exponent describesthe shear thinning region.

Based on assumption (4), the shear rate can be determined in the respective sections $\dot{\gamma}_{a}=\frac{4 \cdot Q \cdot e_{0}}{\pi \cdot r_{a}^{3}}$

$\dot{\gamma}_{b}=\frac{4 \cdot Q \cdot e_{0}}{\pi \cdot r_{b}{ }^{3}}$

The following equation results from formula (1) and (6)

$\Delta p^{*}=\frac{L_{a} \cdot 8 \cdot Q}{\pi \cdot r_{a}^{4}} \cdot \eta_{a}+\frac{L_{b} \cdot 8 \cdot Q}{\pi \cdot r_{b}^{4}} \cdot \eta_{b}$

and can be transformed in a function depending on the viscosity-ratio $\eta_{b} / \eta_{a}$ between section a and $\mathrm{b}$.

$\frac{\Delta p^{*} \cdot \pi}{8 \cdot Q}=\frac{L_{a}}{r_{a}^{4}} \cdot \eta_{a}+\frac{L_{b}}{r_{b}^{4}} \cdot \eta_{b}$

$\frac{\Delta p^{*} \cdot \pi}{8 \cdot Q \cdot \eta_{a}}=\frac{L_{a}}{r_{a}^{4}}+\frac{L_{b}}{r_{b}^{4}} \cdot \frac{\eta_{b}}{\eta_{a}}$

The Cross-WLF parameter $B$ and $C$ in assumption (7) offers a possibility to determine the viscosity-ratio $\eta_{b} / \eta_{a}$ between section $\mathrm{a}$ and $\mathrm{b}$. For this purpose, the zero viscosity of both sections is set equal in formula (14), since the same polymer melt flows through the sections.

$A=\eta \cdot\left(1+(B \cdot \dot{\gamma})^{C}\right)$

$A_{a}=A_{b}$

Eqs. (13) and (14) are transformed in Eq. (15):

$\eta_{a} \cdot\left(1+\left(B \cdot \dot{\gamma}_{a}\right)^{C}\right)=\eta_{b} \cdot\left(1+\left(B \cdot \dot{\gamma}_{b}\right)^{C}\right)$

The viscosity-ratio $\eta_{b} / \eta_{a}$ can be described in Eq. (15).

$\frac{\eta_{b}}{\eta_{a}}=\frac{1+\left(B \cdot \dot{\gamma}_{a}\right)^{C}}{1+\left(B \cdot \dot{\gamma}_{b}\right)^{C}}$

Equation (12), in combination with the viscosity-ratio of Equation (16) results in:

$\frac{\Delta p^{*} \cdot \pi}{8 \cdot Q \cdot \eta_{a}}=\frac{L_{a}}{r_{a}^{4}}+\frac{L_{b}}{r_{b}^{4}} \cdot\left(\frac{1+\left(B \cdot \dot{\gamma}_{a}\right)^{C}}{1+\left(B \cdot \dot{\gamma}_{b}\right)^{C}}\right)$

Together with the shear rate of section $a$ and $b$ from formula (8) and (9), it is possible to determine the viscosity in the capillary channel section a:

$\eta_{a}=\frac{\Delta p^{*} \cdot \pi}{8 \cdot Q \cdot\left(\frac{L_{a}}{r_{a}^{4}}+\frac{L_{b}}{r_{b}^{4}} \cdot\left(\frac{1+\left(B \cdot \dot{\gamma}_{a}\right)^{C}}{1+\left(B \cdot \dot{\gamma}_{b}\right)^{C}}\right)\right)}$ 
and in section b analogously in formula (19).

$$
\eta_{b}=\frac{\Delta p^{*} \cdot \pi}{8 \cdot Q \cdot\left(\frac{L_{b}}{r_{b}^{4}}+\frac{L_{a}}{r_{a}^{4}} \cdot\left(\frac{1+\left(B \cdot \dot{\gamma}_{b}\right)^{C}}{1+\left(B \cdot \dot{\gamma}_{a}\right)^{C}}\right)\right)}
$$

Figure 18 shows the comparison between the CrossWLF viscosity taken from the material data (green dashed), the apparent viscosity (blue) and representative viscosity (black). The error bars are neglected in this diagram, since the standard deviation is too small to be visualized.

The experimentally determined viscosity agrees well qualitatively with the material data of the Cross-WLF model. With the correction factor according to Schümmer, there is also a good quantitative agreement of the predicted curve progression.

There is a small deviation between the experimental $\eta_{e 0}$ and theoretical Cross-WLF viscosity $\eta_{\text {CrossWLF }}$ at lower shear rates. A possible cause could be a deviation of the theoretical to the actual Newtonian plateau viscosity. A reason could be a deviation of the residual moisture content in the polymer pellets during the experiment. Furthermore, the mathematical modeling assumes a homogeneous melt temperature along the flow channel. A possible deviation from this assumption could be a step of the melt temperature in channel section a during the injection phase, which is not detected by the temperature sensor due to the high dynamics. This significant temperature step in the capillary channel may result in a lower viscosity at high shear rates.

Due to the low standard deviation of the viscosity, however, it can be concluded that the deviations are subject to a systematic error and not to the measurement accuracy of the NCV.

\section{Conclusion}

The use of the NCV offers information about the true process conditions during the injection phase. The measured melt temperature in the NCV was about $27^{\circ} \mathrm{C}$ higher than the set target plasticizing temperature. This systematic error was taken into account when calculating the viscosity.

Based on the FEM simulation, a capillary channel geometry with a diameter of $5 \mathrm{~mm}$, a capillary length of $30 \mathrm{~mm}$ and an opening angle of $50^{\circ}$ is defined to be suitable for precisely determining of the pressure difference.

Several steps for signal processing were applied to digitize the analog voltage signals from the sensors and to assign them to the individual injection molding cycles. The data analysis showed that a shift of the left integration boundary by $20 \%$ leads to a better signal-to-noise-ratio of the pressure signal. The calculated measuring inaccuracy of $1.71 \%$ of the NCV appears to be sufficient to detect significant residual moisture and melt temperature fluctuation.
For calculation of the viscosity, a mathematical model of the capillary channel consisting of two sections with different cross-sections is chosen. Based on this subdivision and further assumptions, a model is derived for the determination of the shear rate dependent viscosity in both channel sections.

The calculated viscosity based on experimental data agrees well with the Cross-WLF model based on laboratory data. The high signal-to-noise-ratio proves a high measurement accuracy of the NCV for the determination of the viscosity.

Advantages of this NCV compared to previous solutions are as follows:

- The viscosity can be determined more precisely due to the design, analytical data analysis, and recording of the viscoelastic pressure component. This eliminates the need for a Bagley correction [11], which necessarily requires replacing the capillary channel to determine the inlet pressure drop.

- Due to the lack of need for a replaceable capillary channel, the system design can be significantly reduced in volume and length. This reduces the melt dwell time and, thus, reduces melt degradation.

- The chosen mathematical function can be dynamically adapted to different channel geometries, material systems, and process parameters without changes in the NCV set-up. This mathematical description provides the possibility to control viscosity-related process fluctuations in real time.

The NCV is suitable to determine viscosity inline during the injection process, and therefore, viscosity fluctuations due to residual moisture, melt temperature or batch fluctuations. The use in series production with reduced melt stress and installation space seems appropriate for highly filled thermoplastics as shown with PA6 (30\% glass fiber). The suitability for other thermoplastics with the same or lower glass fiber content seems likely and will be proven in further investigations.

Funding This research work was funded by Ministerium für Wirtschaft, Arbeit und Wohnraum, Baden-Württemberg.

\section{Declarations}

Ethics approval and consent to participate All authors confirm that they follow all ethical guidelines. All authors certify that they have no affiliations with or involvement in any organization or entity with any financial interest or non-financial interest in the subject matter or materials discussed in this manuscript. The authors agree with the participation.

Consent for publication The authors agree with the publication. 
Conflict of interest The authors declare no competing interests.

Open Access This article is licensed under a Creative Commons Attribution 4.0 International License, which permits use, sharing, adaptation, distribution and reproduction in any medium or format, as long as you give appropriate credit to the original author(s) and the source, provide a link to the Creative Commons licence, and indicate if changes were made. The images or other third party material in this article are included in the article's Creative Commons licence, unless indicated otherwise in a credit line to the material. If material is not included in the article's Creative Commons licence and your intended use is not permitted by statutory regulation or exceeds the permitted use, you will need to obtain permission directly from the copyright holder. To view a copy of this licence, visit http://creativecommons.org/licenses/by/4.0/.

\section{References}

1. Michaeli W, Kloubert T, Ehrig F, Berthold J (2000) 'Vorrichtung und Verfahren zur Bestimmung rheologischer Werkstoffdaten', DE000019715630C2, May 31, 2000 [Online]. Available: https:// depatisnet.dpma.de/DepatisNet/depatisnet?action=bibdat\& docid $=$ DE000019715630C2

2. Hopmann C, Theunissen M, Heinisch J (2019) 'Online analysis of melt viscosity during injection moulding with a hot runner rheometer', Dresden, Germany, p. 070022. https://doi.org/10.1063/1.5084866

3. Aho J, Syrjälä S (2011) Shear viscosity measurements of polymer melts using injection molding machine with adjustable slit die. Polym Testing 30(6):595-601. https://doi.org/10.1016/j.polymertesting.2011.04.014

4. Cavic M (2005) 'Kontinuierliche Prozeßüberwachung beim Spritzgießen unter Einbeziehung von Konzepten zur Verbesserung der Schmelzequalität', Shaker, Aachen

5. Gornik C (2008) Viscosity measuring methods for feedstocks directly on injection molding machines Mater Sci Forum 591-593 174 178. https://doi.org/10.4028/www.scientific.net/MSF.591-593.174

6. Fernandez A, Muniesa M, Javierre C (2014) In-line rheological testing of thermoplastics and a monitored device for an injection moulding machine: application to raw and recycled polypropylene. Polym Testing 33:107-115. https://doi.org/10.1016/j.polymertesting.2013.11.008

7. Eben J (2014) Identifikation und Reduzierung realer Schwankungen durch praxistaugliche Prozessführungsmethoden beim Spritzgießen. Univ.-Verl, Chemnitz
8. Kruppa S (2015) Adaptive Prozessführung und alternative Einspritzkonzepte beim Spritzgießen von Thermoplasten. Universität Duisburg-Essen, Duisburg

9. Geyer A, Bonten C (2019) 'Material characterization within the injection molding process', Dresden, Germany, p. 120005. https:// doi.org/10.1063/1.5084895

10. Volpe V, Pantani R (2018) Determination of the effect of pressure on viscosity at high shear rates by using an injection molding machine. J Appl Polym Sci 135(24):45277. https://doi.org/10. 1002/app.45277

11. Bagley EB (1957) End corrections in the capillary flow of polyethylene. J Appl Phys 28(5):624-627. https://doi.org/10.1063/1.1722814

12. Weichert D, Link P, Stoll A, Rüping S, Ihlenfeldt S, Wrobel S (2019) A review of machine learning for the optimization of production processes. The International Journal of Advanced Manufacturing Technology 104(5-8):1889-1902. https://doi.org/10. 1007/s00170-019-03988-5

13. Fernandes C, Pontes AJ, Viana JC, Gaspar-Cunha A (2016) Modeling and optimization of the injection-molding process: a review. Adv Polym Technol 37(2):429-449. https://doi.org/10.1002/adv.21683

14. Kashyap S, Datta D (2015) Process parameter optimization of plastic injection molding: a review. Int J Plast Technol 19(1):1-18. https://doi.org/10.1007/s12588-015-9115-2

15. Menges G, Haberstroh E, Michaeli W, Schmachtenberg E (2011) Menges Werkstoffkunde Kunststoffe, 6. München: Hanser, [Online]. Available: http://deposit.d-nb.de/cgi-bin/dokserv?id= 3791931\&prov $=$ M\&dok_var=1\&dok_ext=htm

16. Osswald T, Rudolph N (2015) Polymer rheology. München [u.a.]: Hanser, [Online]. Available: http://d-nb.info/1030080992/04

17. Laurien E, Oertel H (2013) Numerische Strömungsmechanik: Grundgleichungen und Modelle - Lösungsmethoden - Qualität und Genauigkeit ; mit über 530 Wiederholungs- und Verständnisfragen, 5., Überarb. und erw. Aufl. Wiesbaden: Springer Vieweg

18. [Verfasser/in] Macosko CW (1994) Rheology : principles, measurements, and applications. New York ; Weinheim [u.a.]: Wiley-VCH, [Online]. Available: http://swbplus.bsz-bw.de/bsz042044804cov.htm

19. Schümmer P, Worthoff RH (1978) An elementary method for the evaluation of a flow curve. Chem Eng Sci 33(6):759-763. https:// doi.org/10.1016/0009-2509(78)80054-2

Publisher's Note Springer Nature remains neutral with regard to jurisdictional claims in published maps and institutional affiliations. 